\title{
Influence of Current on Wear Modes and Transition Condition of Current Collecting Materials
}

\author{
Chikara Yamashita ${ }^{1)^{*}}$ and Koshi Adachi ${ }^{2}$ \\ ${ }^{1)}$ Power Supply Technology Division, RAILWAY TECHNICAL RESEARCH INSTITUTE, \\ 2-8-38 Hikari-cho, Kokubunji, Tokyo 185-8540, Japan \\ ${ }^{2)}$ Department of Mechanical Systems Engineering, Graduate School of Engineering, Tohoku University, \\ 6-6-01 Aramaki-Aza-Aoba, Aoba-ku,Sendai, Miyagi 980-8579, Japan \\ *Corresponding author: Chikara Yamashita (yamashita.chikara.52@rtri.or.jp)
}

Manuscript received 21 January 2019; accepted 02 May 2019; published 30 June 2019

(Translation from the Japanese original: Journal of Japanese Society of Tribologists, 58, 7, 2013, 496-503)

\begin{abstract}
It is necessary to understand actual phenomena generated at the electric contacts to suggest the design concept for reducing wear of current collectors such as a contact wire and contact strip in an electric railway. However, rotating wear testing method like pin-ondisk which commonly used to evaluate the wear behavior cannot represent the wear modes of the current collector. In this paper newly linear wear testing method is introduced to represent the wear modes and the wear transition conditions between hard-drawn copper contact wire and iron-based sintered alloy contact strip. As a result, we found that the contact temperature which estimated from contact voltage is dependent on current and load, and then friction and wear properties at the current collectors under current condition are classified into three types by the maximum contact temperature.
\end{abstract}

\section{Keywords}

electric current, contact wire, contact strip, wear mode, wear mode transition condition, linear wear test apparatus, contact voltage, contact temperature

\section{Introduction}

In electric railways, high electric power is supplied to a vehicle through a current collecting system such as overhead lines and a pantograph. The contact wire of the overhad lines and the contact strip of the pantograph are called current collecting materials and are subjected to sliding contact under high current flowing condition with various loads and speeds. Nowadays, the wear of current collecting materials tends to increase because of an increase in vehicle speed and current. Therefore, the wear reduction measures are required for life extention of the current collecting materials.

Conventionally, the wear modes of current collecting materials have been empirically classified into the mechanical wear mode and the electric wear mode [1]. It has been thought that the mechanical wear mode is caused by adhesion between the contact wire and the contact strip under high load condition, and the wear mode transitions to electric wear mode by an arc discharge during contact loss between the contact wire and the contact strip [2, 3]. Teraoka [4] and Kono et al. [5] reported that the wear properties of current collecting materials cannot be approximated with Holm's law because of the arc discharge and huge wear is observed under low load condition. Nagasawa et al. $[6,7]$ proposed measures for corrugated wear reduction with a focus on the arc discharge. Although many researchers have reported that the wear rate of current collecting materials increases by the arc discharge, Iwase [1], Kono [2] and Kimura et al. [8] also reported that the wear rate of the contact wire becomes significantly small at the position where the arc discharge always occurs. Therefore, it could be said that the wear mechanism of the electric wear of current collecting materials cannot be explained only by the arc discharge and has not been clarified yet. Nagasawa et al. [9] classified the wear modes of current collecting materials from a viewpoint of the shape of wear debris, but the generating mechanism of wear debris was not clarified. Therefore, it also could be said that the transition condition between wear modes has not been clarified yet.

In this paper, the authors newly developed a wear test apparatus which enables to reproduce the wear condition in the field, and classified the wear mode under current flowing condition. Finally, the authors clarified the mechanism of the electric wear and the transition condition between wear modes. 


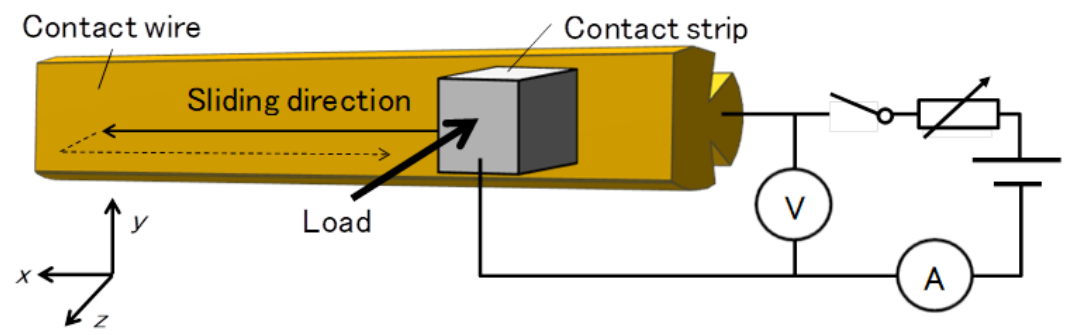

Fig. 1 Schematic image of linear wear test apparatus

\section{Experimental method}

\subsection{Wear test apparatus}

Conventionally, some large rotary wear test apparatus like a pin-on-disk or a pin-on-ring which can run at high speed have been used to evaluate the wear of current collecting materials under the railway field condition such as running speed and current. However, it has been pointed out that those apparatus can hardly reproduce the actual wear behavior even if they can reproduce the running condition in the field $[10,11]$. The reason has been said that various wear modes occur simultaneously during the test because an arc discharge occurs even under high load condition due to the huge fluctuation of the load. It has been also pointed out that the influence of heat on wear of the contact wire in rotary wear tests is larger than that in the field because the interval of contact is too short at high speed rotation.

Based on the above, the authors determined the purpose of experiment with a focus on the clarification of the wear properties of current collecting materials under current flowing condition, with the following items taken into account as four main points.

(1) It is required to suppress the mixture of wear modes in order to extract individual wear mode according to the load of the contact strip in the field. For this purpose, the fluctuation of the load should be suppressed during the wear test.

(2) The contact interval of the contact wire should be set in consideration of the passage interval of pantographs in order to reproduce the heat influence on the wear of the contact wire in the field.

(3) It is required to focus on only the heat caused by the current flowing in order to clarify the mechanism of the electric wear mode. Therefore, the friction heat should be suppressed by setting the sliding speed low.

(4) The contact voltage between the contact wire and the contact strip should be measured precisely in order to estimate the contact condition at the wear surface and the temperature at contact points precisely.

The wear test apparatus shown in Fig. 1 is newly developed in consideration of the above points. Since the contact wire is set linear and the contact strip slides on the wire intermittently, the apparatus is named linear wear test apparatus. A ball screw

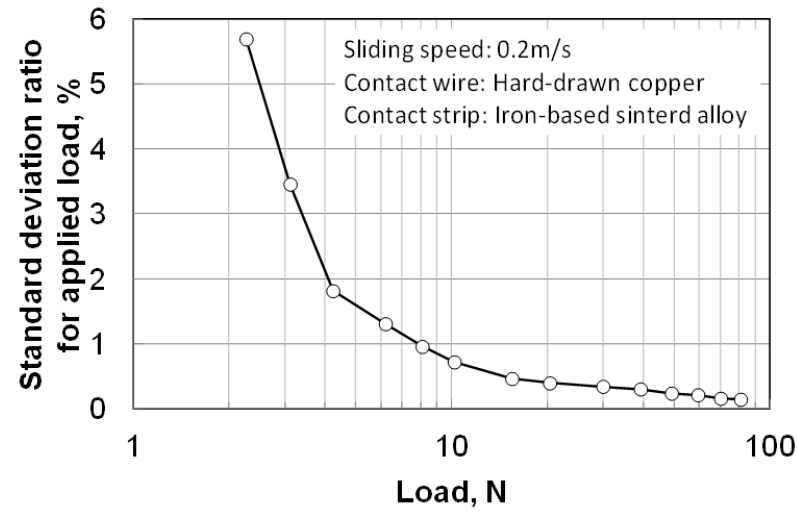

Fig. 2 Standard deviation ratio for applied load (Sliding speed: $0.2 \mathrm{~m} / \mathrm{s}$ )

is used for the moving mechanism of the contact strip in $z$ direction, and an electromagnetic linear actuator is used for the moving mechanism of the contact strip in $x$ direction. The load is applied by pressing the contact strip to the contact wire via a spring set behind the contact strip. The load and the friction force are measured with load cells installed with springs in the $z$ direction and $x$ direction of the contact strip. The contact strip slides on the contact wire in one direction by unloading on its return stroke, and the current is flowed only during its sliding by controlling the switch synchronously.

Figure 2 shows the standard deviation ratio for applied load. In the case of the sliding speed with $1 \mathrm{~m} / \mathrm{s}$ or less, the fluctuation of the load can be small and the maximum value of the standard deviation ratio can be less than $6 \%$. Consequently it is expected to suppress the mixture of plural wear modes. In addition, the linear wear test apparatus does not need a slip ring which often results in noise in measured the contact voltage signal. Hence, it is expected to improve the accuracy in measuring the contact voltage.

\subsection{Wear test specimen}

Table 1 shows the sorts and components of the contact wire and the contact strip as wear test specimens. A hard-drawn copper contact wire in conformity to JIS E 2101 "Hard-Drawn Grooved Trolley Wires" with a nominal cross section of 170

Table 1 Sort and components of specimen

\begin{tabular}{c|c|c|c|c|c|c}
\hline Specimen & Sort & Component & $\begin{array}{c}\text { Density, } \\
\mathrm{g} / \mathrm{mm}^{3}\end{array}$ & $\begin{array}{c}\text { Hardness, } \\
\mathrm{MPa}\end{array}$ & $\begin{array}{c}\text { Resistivity, } \\
\mu \Omega \mathrm{m}\end{array}$ & $\begin{array}{c}\text { Melting point, } \\
\mathrm{K}\end{array}$ \\
\hline Contact wire & GT-170 & $\mathrm{Cu}(99.9 \%)$ & 8.91 & 895 & $1.77 \times 10^{-2}$ & 1,334 \\
\hline Contact strip & TF5A & $\mathrm{Fe}(78.6 \%), \mathrm{Cr}(16.5 \%), \mathrm{S}(0.9 \%)$ & 7.10 & 960 & 0.40 & 1,646 \\
\hline
\end{tabular}


$\mathrm{mm}^{2}$ was used for the specimen of the contact wire (GT-170), and an iron-based sintered alloy was used for the specimen of the contact strip (TF5A). The reason for choosing GT-170 and TF5A is to facilitate to identify where wear debris and transfer layers come from in component analysis with the EPMA (electron probe $\mathrm{X}$-ray micro analyzer).

In order to keep facial contact between the contact wire and the contact strip, the contact surface of the contact wire specimen was grinded so as to make it flat and the contact wire was shaped into cubic. The width of the contact surface of the contact wire was $15 \mathrm{~mm}$ or more and the size of contact strip cube was $10 \mathrm{~mm} \times 10 \mathrm{~mm} \times 10 \mathrm{~mm}$. In order to suppress partial contact, the wear test was carried out after running-in without current until the wear trace was observed on the whole contact surface of the contact strip.

The sectional wear area of the contact wire was calculated from cross sectional profiles measured by a profilometer before and after the wear test as shown in Fig. 3. Since the width of the contact wire was larger than that of the contact strip, the non-contact plane was used for reference plane. The scanning direction of the profilometer was $y$ direction in Fig. 1 and five profiles were measured at intervals of $5 \mathrm{~mm}$ in $x$ direction. The wear rate of the contact wire $W_{s t}\left[\mathrm{~mm}^{2} / \mathrm{N} \cdot\right.$ cycle] was calculated by the following equation by using the average value of the sectional wear area $A\left[\mathrm{~mm}^{2}\right]$ obtained from five measurement results.

$$
W_{s t}=\frac{A}{P \cdot N}
$$

where $P$ is the load $[\mathrm{N}], N$ is the number of sliding cycle [cycle]. The specific wear rate of the contact strip $W_{\mathrm{ss}}\left[\mathrm{mm}^{3} / \mathrm{N} \cdot \mathrm{m}\right]$ was calculated by the following equation.

$$
W_{s s}=\frac{\Delta m}{\rho \cdot P \cdot L_{s}}
$$

where $\Delta m$ is the decrease in mass of the contact strip during the wear test $[\mathrm{g}], \rho$ is the mass density of the contact strip $\left[\mathrm{g} / \mathrm{mm}^{3}\right]$, $L_{s}$ is the total sliding distance [m]. It should be noted that $\Delta m$ includes the wear during the running-in, and the calculated value of the specific wear rate is slightly larger than the real one.

\subsection{Wear test conditions}

Table 2 shows the wear test conditions, i.e., friction condition, voltage and current. A cycle of the wear tests was carried out 3,000 times under each condition and the wear rate of the contact wire and the specific wear rate of the contact strip were calculated after the test. The authors selected the sliding

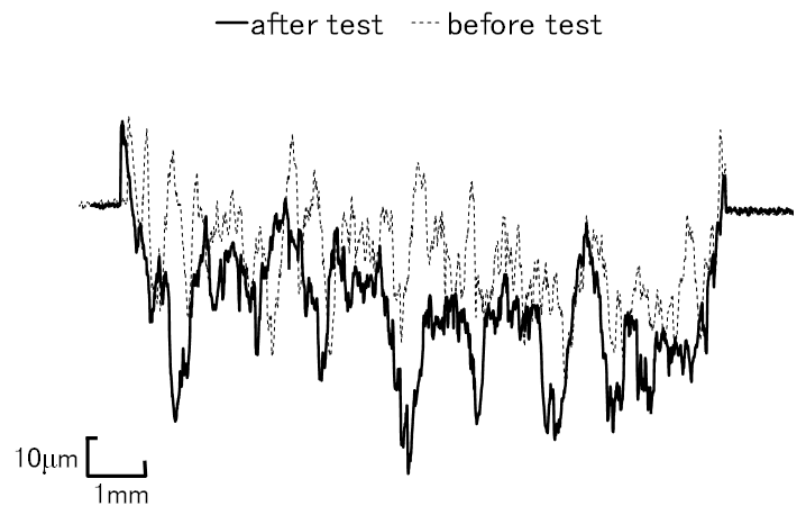

Fig. 3 Cross sectional profiles of contact wire
Table 2 Wear test conditions

\begin{tabular}{l|l}
\hline Load, $\mathrm{N}$ & $2 \sim 80$ \\
\hline Sliding speed, $\mathrm{m} / \mathrm{s}$ & 0.2 \\
\hline Voltage, $\mathrm{V}$ & $\mathrm{DC} 100$ \\
\hline Current, $\mathrm{A}$ & $0,50,80,100$ \\
\hline Sliding distance, $\mathrm{mm}$ & 25 \\
\hline Number of sliding cycle & 3,000 \\
\hline Friction interval, sec & approximately 5.0 \\
\hline
\end{tabular}

speed condition so as to suppress the friction heat and contact loss between the contact wire and the contact strip. A friction interval of about 5 seconds was applied during the wear test corresponding to the intervals of the passage of pantographs on a real train, if there are multiple pantographs on a train set.

\section{Experimental results}

\subsection{Contact loss ratio}

Figure 4 shows the relationship between the load and the contact loss ratio calculated by dividing the total time duration of the arc discharge by the sliding time. Since the minimum voltage of the arc discharge between copper materials is approximately $13 \mathrm{~V}$ [12], the authors regarded cases where the contact voltage exceeded $10 \mathrm{~V}$ as occurrence the arc discharge. The sampling frequency was set to $10 \mathrm{kHz}$ during the measurement of the contact loss ratio. According to Fig. 4, the contact loss occurs at a load of less than $6 \mathrm{~N}$, and the maximum contact loss ratio is less than $0.5 \%$. This result means that the fluctuation of the load is sufficiently small during the wear test.

\subsection{Friction coefficient and wear rate}

Figure 5 shows the relationship between the load and some wear-related indexes associated to the wear rate of the contact wire, the specific wear rate of the contact strip and the friction coefficient under four electric current conditions of $0 \mathrm{~A}, 50 \mathrm{~A}$, $80 \mathrm{~A}$ and $100 \mathrm{~A}$. According to Fig. 5, it is found that the friction coefficient and the wear rates under non-current condition remain almost constant regardless of the load variation. Figure 6 shows the SEM (Scanning Electron Microscope) images and the EPMA images of the typical wear surfaces and wear debris under non-current conditions. Component analysis was carried

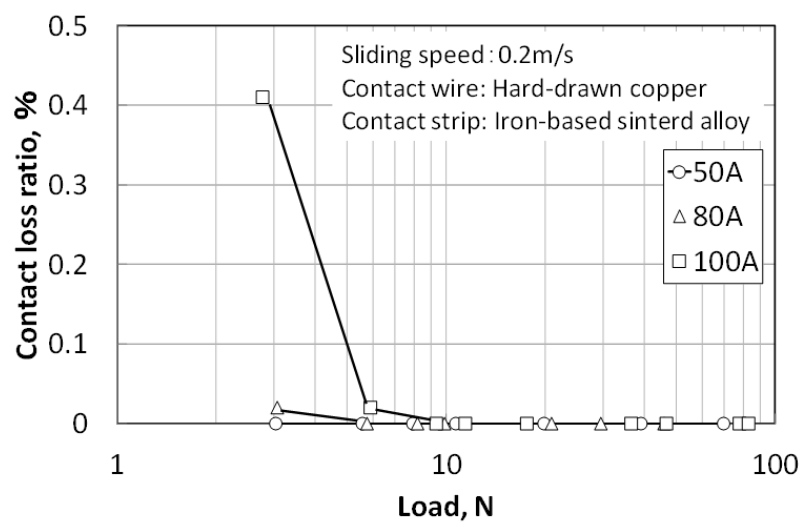

Fig. 4 Relation between load and contact loss ratio (Sliding speed: $0.2 \mathrm{~m} / \mathrm{s}$ ) 


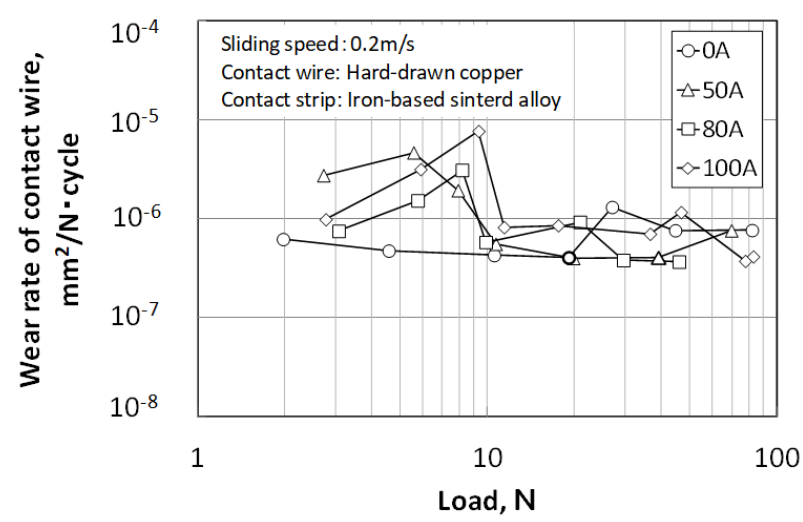

(a) Wear rate of contact wire

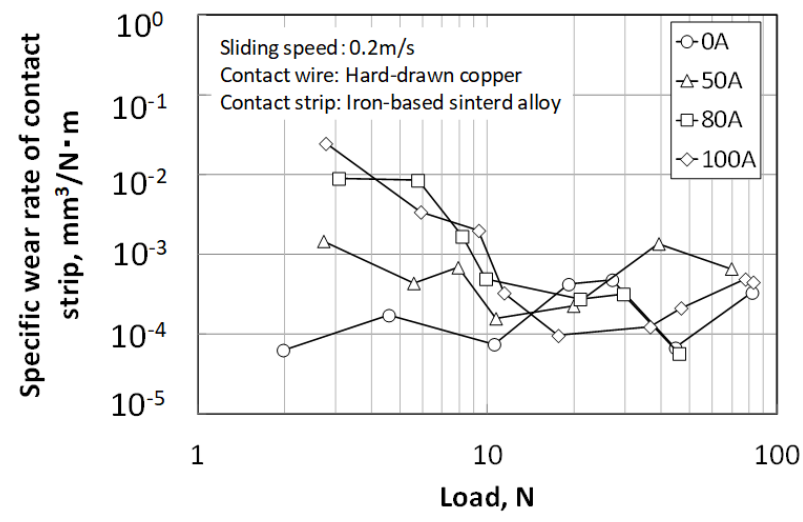

(b) Specific wear rate of contact strip

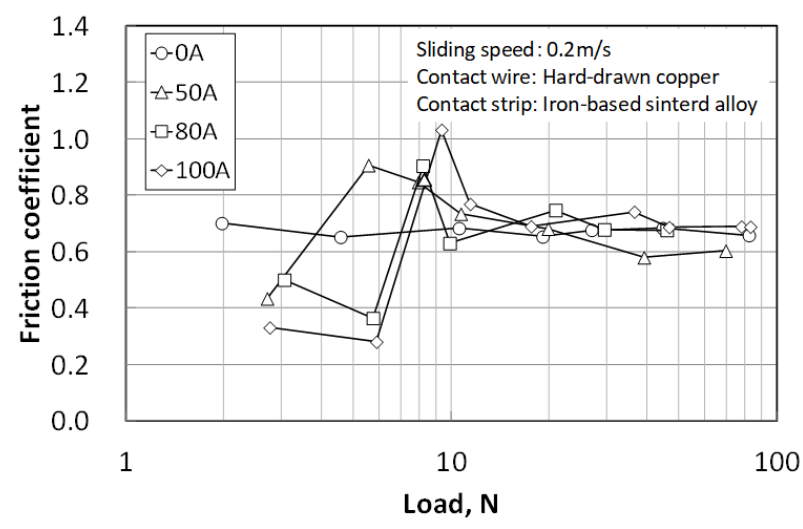

(c) Friction coefficient

Fig. 5 Relation between load and friction- wear properties of current collecting materials

out on $\mathrm{Cu}$ which is the main component of the contact wire and Fe which is the main component of the contact strip. According to Figs. 6 (a) and (b), shearing traces in the sliding direction are observed on both surfaces, and there is a few transfer layer on both surfaces. According to Fig. 6 (c), the flake-shaped wear debris are mainly composed of copper flakes. As a result, the wear mode observed under non-current condition should be classified as a mechanical wear mode caused by adhesion and delamination.

On the other hand, friction and wear properties under current flowing conditions can be classified into three types according the friction coefficient, the wear rates and the wear
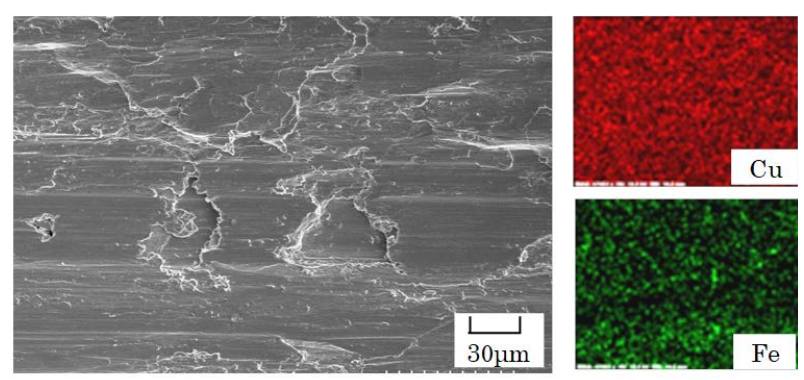

(a) Contact wire surface
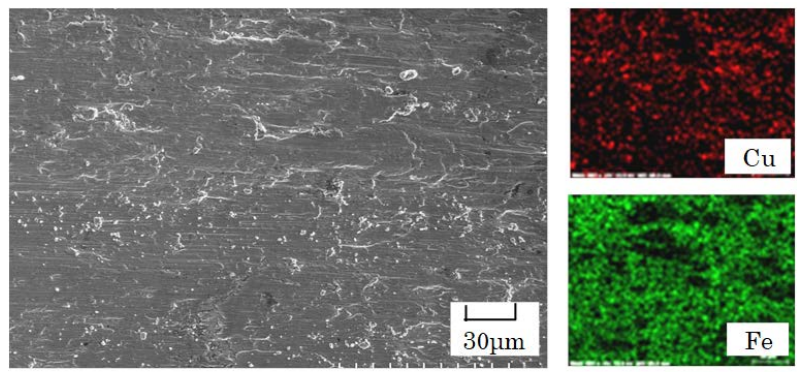

(b) Contact strip surface
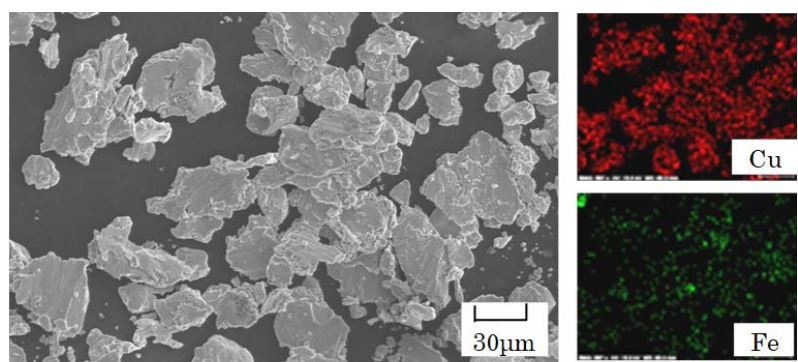

(c) Wear debris

Fig. 6 SEM-EPMA analysis of wear surface and wear debris (Load: $27 \mathrm{~N}$, sliding speed: $0.2 \mathrm{~m} / \mathrm{s}$, current: $0 \mathrm{~A}$ )

debris as follows.

(1) Load conditions of $10 \mathrm{~N}$ or more; According to Fig. 5, the friction coefficient and the wear rates under current flowing conditions are approximately equal to the values obtained under non-current condition. Under such load conditions, the wear surfaces and the wear debris are the same as those shown in Fig. 6, and no melting traces can be observed even with current flow. As a results, the wear mode is considered as the mechanical wear mode under such load conditions.

(2) Load conditions of 6-10 N; According to Fig. 5 (a), the maximum wear rates of the contact wire are observed under current flowing conditions, and their values are one order of magnitude larger than that under non-current condition. The load under which the maximum wear rate of the contact wire is observed increases as the current increases. Under the load conditions, the friction coefficient under current flowing condition is larger than that under noncurrent condition as shown in Fig. 5 (c).

Figure 7 shows the SEM and EPMA images of the typical wear surfaces and wear debris under the load conditions. According to Figs. 7 (a) and (b), the traces of melting copper, which is the main component of the contact wire, are observed on the contact wire surface, and transferred copper is observed on the contact strip surface. On the other hand, no melting traces of iron is observed on the contact 

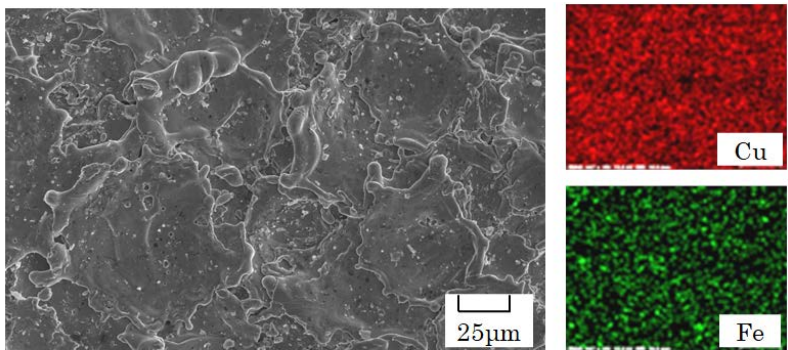

(a) Contact wire surface

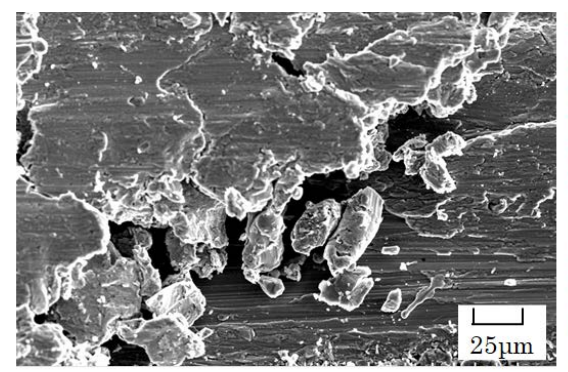

(b) Contact strip surface
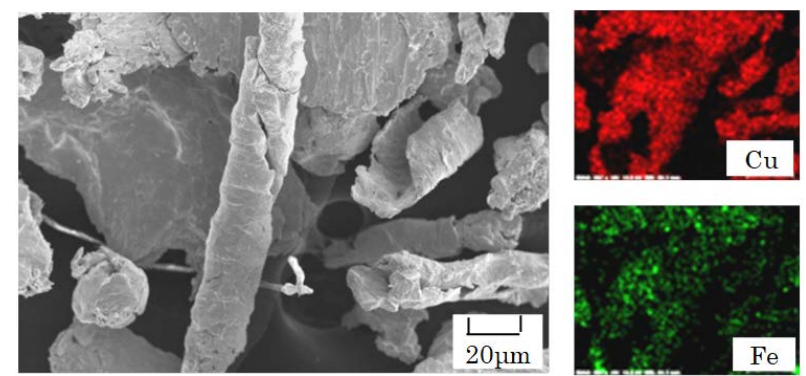

(c) Wear debris

Fig. 7 SEM-EPMA analysis of wear surface and wear debris (Load: $9.3 \mathrm{~N}$, sliding speed: $0.2 \mathrm{~m} / \mathrm{s}$, current: $100 \mathrm{~A}$ )

strip. According to Figs. 7 (b) and (c), the roll-shaped wear debris drop out from the transferred copper layer on the contact strip. In this paper, this wear mode is called electric wear mode I because the influence of the current on the wear properties is confirmed.

(3) Load conditions of $6 \mathrm{~N}$ or less; According to Fig. 5 (b), the specific wear rate of the contact strip under current flowing conditions significantly increase as the load decreases, and their values are one or two order of magnitude larger than that under non-current condition. The friction coefficients become lower than that under non-current as shown in Fig. 5 (c). On the other hand, the wear rate of the contact wire under the load conditions decreases as the load decreases as shown in Fig. 5 (a). In particular, under the condition of a load of about $3 \mathrm{~N}$ and a current of $80 \mathrm{~A}$ or more, the wear rate of the contact wire is approximately equal to the values obtained under non-current condition. It should be noted that the arc discharge occurs under the conditions as shown in Fig. 4.

Figure 8 shows the SEM and EPMA images of the typical wear surfaces and wear debris. According to Figs. 8 (a) and (b), the traces of melting iron, which is the main component of the contact strip, are observed on the contact strip, and transferred iron is observed on the contact wire. It should be noted that there is no melted copper on the contact wire surface. According to Fig. 8 (c), the large flake-shaped wear
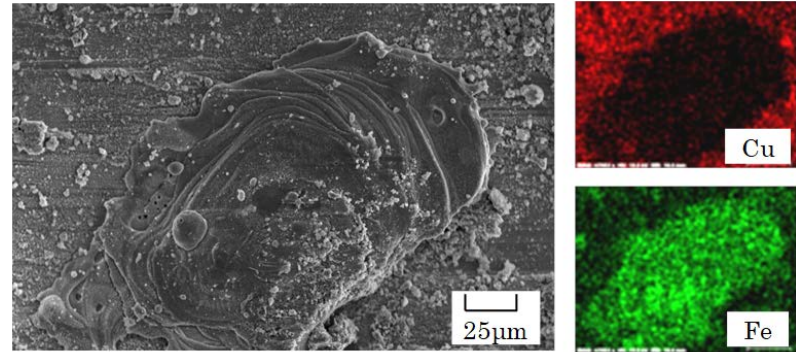

(a) Contact wire surface
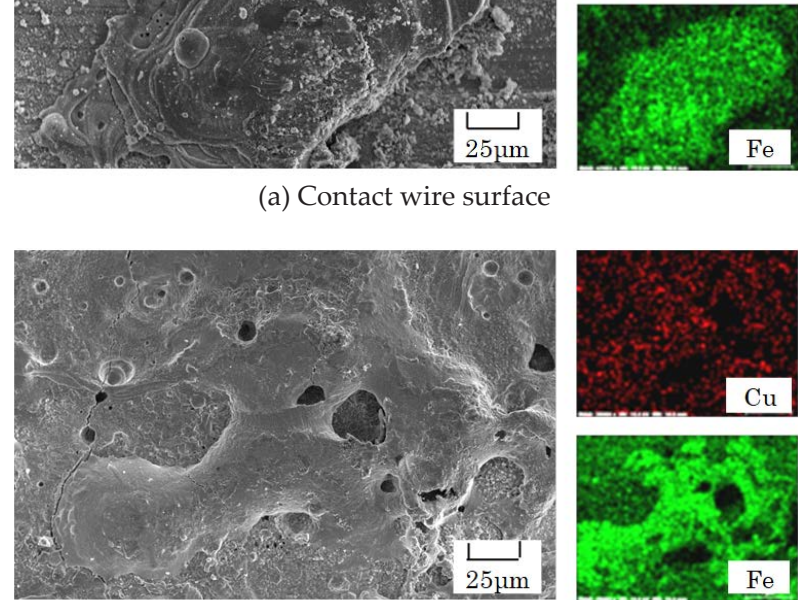

(b) Contact strip surface
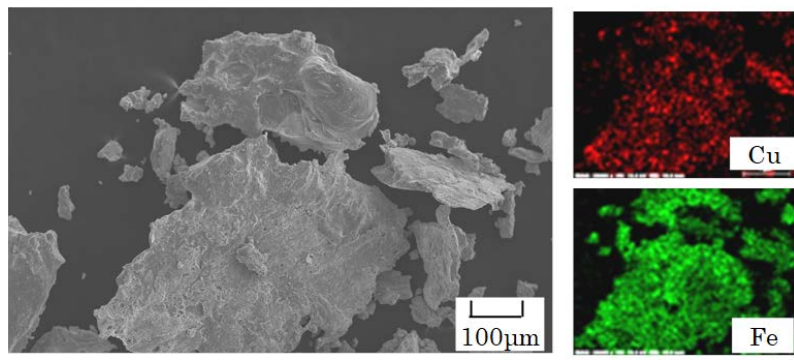

(c) Wear debris

Fig. 8 SEM-EPMA analysis of wear surface and wear debris (Load: $2.7 \mathrm{~N}$, sliding speed: $0.2 \mathrm{~m} / \mathrm{s}$, current: $100 \mathrm{~A}$ )

debris are mainly composed of iron. In this paper, this wear mode is called electric wear mode II because the influence of the current on the wear properties differently from the electric wear mode I is confirmed.

The conditions for the occurrence of these wear modes can be organized as Fig. 9 by the load and the current. In the next chapter, the authors discuss the transition conditions between these wear modes.

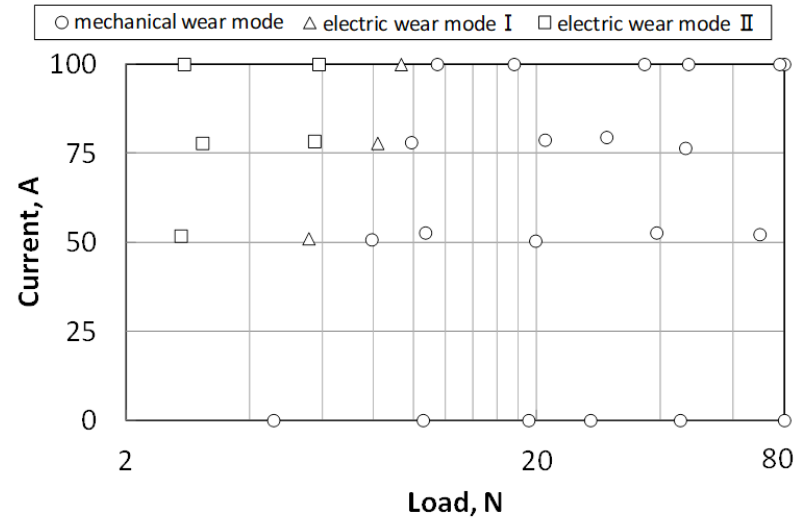

Fig. 9 Classification of wear mode under load and current (Sliding speed: $0.2 \mathrm{~m} / \mathrm{s}$ ) 


\section{Discussion}

As major features between three wear modes described in chapter 3, no melting trace were observed on the contact wire and the contact strip in the mechanical wear mode, melting traces were observed only on the contact wire in electric wear mode I, and melting traces were observed only on the contact strip in electric wear mode II. According these observation results, it is thought that the melting condition of current collecting materials deeply affects the transition condition of the wear modes.

Although it is difficult to measure the temperature of small contact points directly, " $\varphi-\theta$ Theory" which proposed by Holm [13] for estimating the maximum contact temperature $T_{\max }[\mathrm{K}]$ from the contact voltage $V_{c}[\mathrm{~V}]$ by the following equation can be applicable.

$$
T_{\max }=\left(\frac{V_{c}^{2}}{4 L}+T_{0}^{2}\right)^{1 / 2}
$$

where $L$ is the Lorentz number $\left(=2.4 \times 10^{-8}\left[\mathrm{~V}^{2} / \mathrm{K}^{2}\right]\right)$, and $T_{0}$ is the bulk temperature (= ambient temperature $300[\mathrm{~K}])$. Since the contact voltage between the contact wire and the contact strip can be measured precisely with the linear wear test apparatus and the influence of the friction heat on the temperature at contact points is negligible because of lower sliding speed as described in section 2.1, the maximum contact temperature can be calculated with Eq. (3).

Figure 10 shows the examples of the waveforms of the current and the contact voltage in the case of static and sliding conditions of the contact strip under the current condition of 100 A. According to Fig. 10 (a), the waveform of the contact voltage in the case of static condition is similar to that of a current containing ripple component which is supplied by rectification, and noises on the waveforms are hardly observed. On the other hand, the fluctuation of the contact voltage in the case of sliding condition shown in Fig. 10 (b) can be interpreted as a result of the small fluctuation of the load and the change in the number of contact points. Since the electric heat becomes maximum when the contact voltage is maximum, the authors evaluate the electrical heat by using a statistic maximum contact voltage which is calculated by an average value of the contact voltage and $3 \sigma$, where $\sigma$ is the standard deviation of the contact voltage. Figure 11 shows the relationship between the load and the statistic maximum contact voltage under three current conditions. In this figure, it is found that the statistic maximum contact voltage increases as the load decreases and the current increases. Figure 12 shows the maximum contact temperature calculated from Fig. 11 and Eq. (3) for the load and the current shown in Fig. 9. In this calculation, the temperature under noncurrent conditions was assumed to be $300 \mathrm{~K}$ because the friction heat can be neglected. The melting point of the contact wire 1,334 $\mathrm{K}$ and that of the contact strip $1,646 \mathrm{~K}$ are also indicated with broken lines in this figure.

According to Fig. 12, the transition condition from the mechanical wear mode to the electric wear mode I approximately coincides with the condition under which the maximum contact temperature reaches the melting point of the contact wire 1,334 K. In other words, the wear mode transition results from the melting of the contact wire. Under current flowing condition, it is thought that the contact temperature rises enough to soften the materials even the contact wire does not melt. However, the influence of material softening on the

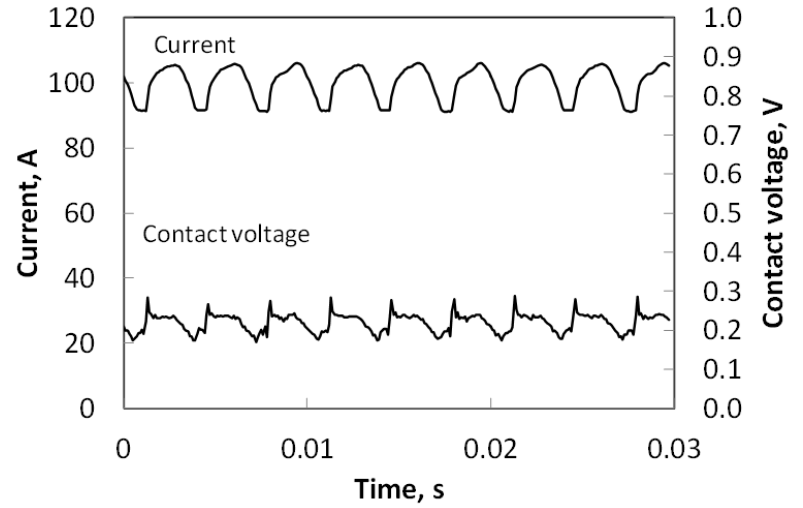

(a) Stationary (Sliding speed: $0 \mathrm{~m} / \mathrm{s}$ )

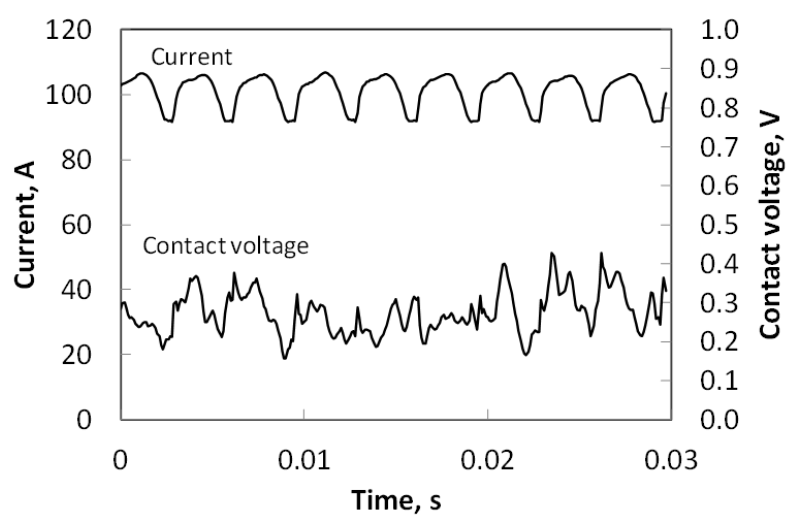

(b) Sliding (Sliding speed: $0.2 \mathrm{~m} / \mathrm{s}$ )

Fig. 10 Measured waveform of current and contact voltage (Current: 100 A)

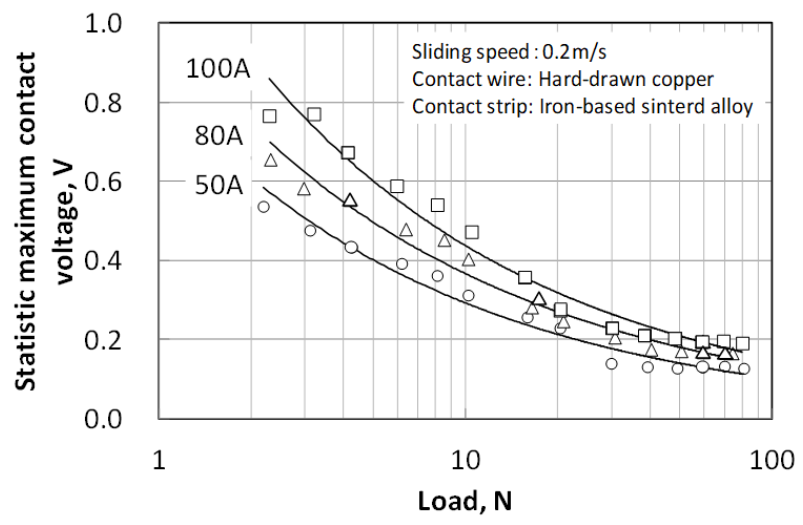

Fig. 11 Relation between load and statistic maximum contact voltage (Sliding speed: $0.2 \mathrm{~m} / \mathrm{s}$ )

wear mode transition and wear properties shown in Fig. 5 cannot be observed.

According to Fig. 12, the transition condition from the electric wear mode I to the electric wear mode II approximately coincides with the condition under which the maximum contact temperature reaches the melting point of the contact strip 1,646 $\mathrm{K}$. In other words, the wear mode transition results from the melting of the contact strip. It is found that the electric wear mode I in which the wear rate of the contact wire becomes maximum occurs under the condition that only the contact wire 


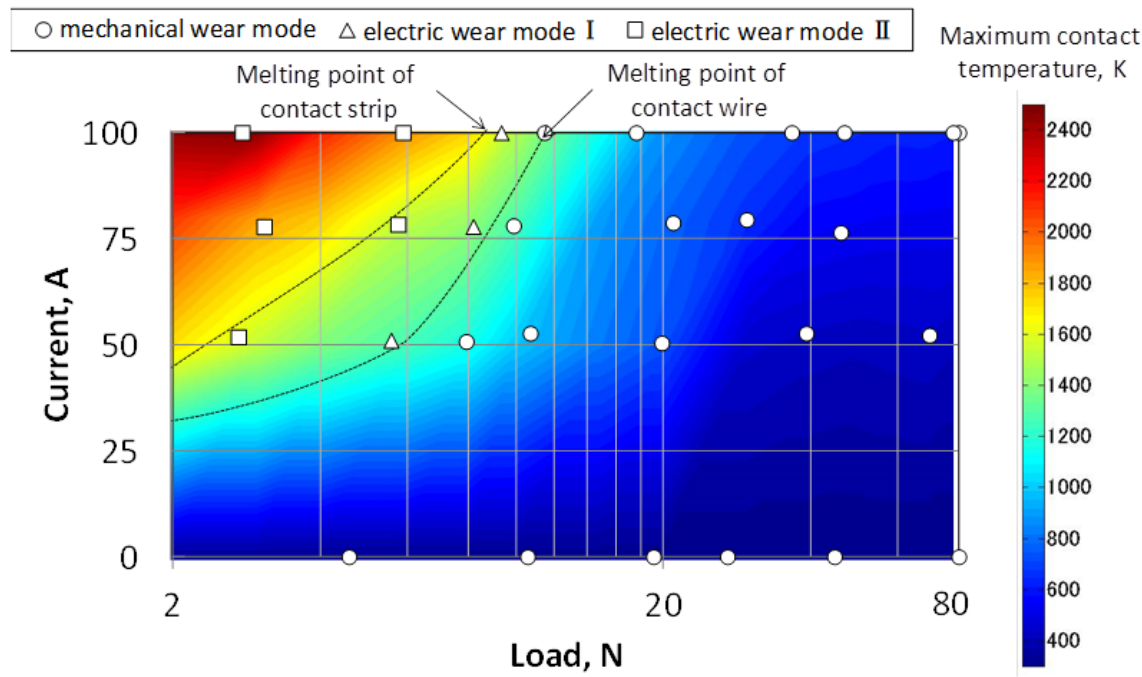

Fig. 12 Relation between wear mode and maximum contact temperature (Sliding speed: $0.2 \mathrm{~m} / \mathrm{s}$ )

melts, and the electric wear mode II occurs under the condition that the contact temperature rises over the melting point of the contact strip and the arc discharge occurs. According to the results, it is concluded that the electric wear mode I is caused not by an arc discharge, which has been thought to be the main cause of the wear of the contact wire, but by a melting bridge [14] of the contact wire. Since the contact strip intermittently slides on the surface of the contact wire during the wear test, the melting bridge of the contact wire might be cooled and welded to the contact strip in the case of the electric wear mode I. Therefore, it is thought that the friction coefficient under the electric wear mode I shown in Fig. 5 (c) increases compared to the mechanical wear mode because force to break the welding spot is added to the friction force. It should be noted that the load range where the electric wear mode I occurs is so narrow as to be several $\mathrm{N}$ under each current condition so that this wear mode can only be observed by using the apparatus with small load fluctuation as shown in Fig. 2. On the other hand, it is concluded that the electric wear mode II is caused by the arc discharge and the melting of the contact strip. Since the surface of the contact strip slides continuously, the melting bridge of the contact strip cannot be cooled and a melting layer formed between the contact strip and the contact wire. Therefore, it is thought that the friction coefficient under the electric wear mode II shown in Fig. 5 (c) decreases compared to the mechanical wear mode because the melting layer behaves as a lubricant. However, although the temperature at the contact points under the electric wear mode II should also exceed the melting point of the contact wire, the melting trace of the contact wire cannot be observed as shown in Fig. 7 (a). The mechanism of this phenomenon cannot be clarified in this paper. A verification test and a temperature analysis will lead to a deeper understanding of this issue.

Based on the discussion in this chapter, the phenomenon in which the wear rate of a contact wire becomes small at the position where arc discharge always occurs in the railway field $[1,2]$ can be explained by the fact that the electric wear mode II might always occur if the arc discharge always occurs, and therefore the melting of the contact wire might be suppressed. In contrast, the phenomenon in which the wear rate of the contact wire becomes large at the position where contact loss often but not always occurs in the railway field $[4,5]$ can be explained by the fact that the electric wear mode I in which only the contact wire melts might often occurs, so the wear of the contact wire is promoted.

In the future, it is possible to propose guidelines for wear reduction and the development of better current collecting materials by generalization of the results obtained in this paper and clarification of the wear mechanism under current flowing condition. In addition, it is necessary to consider the influence of friction heat on wear properties under high speed condition such as actual operating speed.

\section{Conclusions}

In this study, the authors classified the wear modes between a hard-drawn copper contact wire and an iron-based sintered alloy contact strip under current flowing condition into three types as follows by using a linear wear test apparatus which is newly developed for clarifying wear properties under current flowing condition .

(1) In the case where the contact temperature is lower than the melting point of the contact wire and the contact strip, the wear mode becomes the mechanical wear mode. In this wear mode, the friction and wear properties under current flowing condition do not depend on the current and are approximately similar to those under non-current condition.

(2) In the case where the contact temperature is higher than the melting point of the contact wire and lower than that of the contact strip, the wear mode becomes the electric wear mode I. In this wear mode, the wear rate of the contact wire and the friction coefficient increase significantly compared to those under non-current condition.

(3) In the case where the contact temperature is higher than the melting point of the contact strip, the wear mode becomes the electric wear mode II. In this wear mode, the friction coefficient and the wear rate of the contact wire decrease compared to those under non-current condition, and the specific wear rate of the contact strip increases significantly compared to that under non-current condition.

\section{References}

[1] Iwase, M., "Current Collecting by the Pantograph and Its Wear (III)," Railway Technical Research Report, 217, 1961 (in Japanese). 
[2] Kohno, A., Ohyabu, H. and Soda, N., "Effect of Discontact Arc on Wear of Materials for Current Collection (Part 1) - In the Case of Load Change -," Journal of Japan Society of Lubrication Engineers, 27, 4, 1982, 283-287 (in Japanese).

[3] Kohno, A., Ohyabu, H. and Soda, N., "Effect of Discontact Arc on Wear of Materials for Current Collection (Part 2) - In the Case of Various Sliding Velocities -," Journal of Japan Society of Lubrication Engineers, 27, 7, 1982, 527-532 (in Japanese).

[4] Teraoka, T., "Wear of Pantograph Contact Strips," Journal of Japan Society of Lubrication Engineers, 22, 1, 1977, 11-16 (in Japanese).

[5] Kohno, A., Ohyabu, H. and Soda, N., "Effect of Electric Current on Wear of Materials for Current Collection," Journal of Japan Society of Lubrication Engineers, 26, 8, 1981, 562-567 (in Japanese).

[6] Nagasawa, H. and Aboshi, M., "Study on Undulating Wear of Contact Wire on Narrow-Gauge Lines," RTRI Report, 2, 4, 1988, 4654 (in Japanese).

[7] Nagasawa, H. and Aboshi, M., “Undulating Wear of Contact Wire on Electric Railways," Journal of Japanese Society of Tribologists,
35, 2, 1990, $79-84$ (in Japanese).

[8] Kimura, Y., Mishina, Y. and Ohmori, T., "Effects of Electric Current on Wear of Current Collectror," Journal of Japanese Society of Tribologists, 52, 10, 2007, 737-743 (in Japanese).

[9] Nagasawa, H. and Kato, K., "Wear Mechanism of Copper Alloy Wire Sliding against Iron-Base Strip under Electric Current," Wear, 216, 2, 1988, 179-183

[10] Iwase, M., “À la Carte of Current Collection,” Ken-yusha, Tokyo, 1998, 21-23 (in Japanese).

[11] He, D. H., Manory, R. and Sinkis, H., "A Sliding Wear Tester for Overhead Wires and Current Collectors in Light Rail Systems," Wear, 239, 1, 2000, 10-20.

[12] Ho, S., "Electrical Contacts and Switching Contacts," Kanehara, Tokyo, 1962, 197 (in Japanese)

[13] Holm, R., "Electric Contacts: Theory and Applications, 4th ed.," Springer, Berlin, 1967, 60-64

[14] Takagi, T., "Arc Discharge Phenomena of Electric Contacts," Corona, Tokyo, 1995, 56-67 (in Japanese) 